DOI: $10.5902 / 1984644424254$

\title{
Representações do professor generalista acerca do papel do professor especialista: análise da produção científica em educação especial no período de 2008 a 2015
}

Generalist teacher representations about the specialist teacher role: analysis of scientific production in special education in the period from 2008 to 2015

Representaciones del profesor generalista acerca del papel del profesor especialista: análisis de la producción científica en educación especial en el período de 2008 a 2015

\section{* Claudia Regina Mosca Giroto}

Professora doutora na Universidade Estadual Paulista Júlio de Mesquita Filho, Marília, São Paulo, Brasil. claudia.mosca@marilia.unesp.br

** Natália Morato Mesquita Sabella Graduanda na Universidade Estadual Paulista (UNESP), Marília, São Paulo, Brasil. nataliasabella_10@hotmail.com

\section{*** Jessica Mariane Rodrigues de Lima}

Graduanda na Universidade Estadual Paulista (UNESP), Marília, São Paulo, Brasil. jessicarlima@marilia.unesp.br

Recebido: 08 de outubro de 2017

Aprovado: 10 de outubro de 2017

\section{RESUMO}

O presente trabalho objetivou identificar e analisar a produção científica nacional divulgada em periódicos da área de Educação Especial sobre as representações do professor generalista acerca do papel do professor especialista no processo de escolarização dos alunos público-alvo da Educação Especial. A pesquisa bibliográfica considerou, por ocasião da coleta de dados, os periódicos classificados nos extratos de B2 a A1: a Revista de Educação Especial de Santa Maria (REESM); e a Revista Brasileira de Educação Especial (RBEE), respectivamente, bem como os artigos publicados nesses periódicos, no período de 2008 a 2015, relacionados à temática em questão. Para a coleta de dados foram considerados, inicialmente, os sumários, seguidos dos resumos e artigos na íntegra que atenderam ao objetivo proposto. Foi efetuada análise qualiquantitativa, subsidiada pelos indicadores: ano e quantidade de publicação; tipo de autoria; área de formação dos autores e coautores; e temas relacionados às representações do professor generalista sobre o papel do especialista. Foi constatada maior concentração de artigos publicados em 2015 no periódico B2, bem como predomínio: de autoria em dupla nos dois periódicos; da Educação como principal área de formação dos autores e coautores; e da reflexão sobre 
DOI: $10.5902 / 1984644424254$

concepções de professores acerca da inclusão escolar como subtema relacionado à temática em questão. A escassez de publicações sobre a temática ora investigada revelou a necessidade de divulgação de estudos que ampliem as reflexões e proposições sobre a mesma.

Palavras-chave: Professor generalista; Professor especialista; Educação especial.

\section{ABSTRACT}

The present work aimed to identify and analyze the national scientific production published in Special Education journals on the representations of the generalist teacher about the role of the specialist teacher in the process of schooling of the target public students of Special Education. The bibliographical research considered, at the time of data collection, the periodicals classified in extracts from B2 to A1: the Revista de Educação Especial de Santa Maria (REESM); and the Brazilian Journal of Special Education (RBEE), respectively, as well as the articles published in these periodicals, from 2008 to 2015, related to the theme in question. For the data collection, the summaries were initially considered, followed by the abstracts and articles in full that met the proposed objective. Qualitative analysis was carried out, subsidized by indicators: year and quantity of publication; type of authorship; area of training of authors and co-authors; and topics related to the representations of the generalist teacher about the role of the specialist. It was found a greater concentration of articles published in 2015 in the periodical B2, as well as predominance: of authorship in double in the two periodicals; education as the main area of training for authors and co-authors; and reflection on teachers' conceptions about school inclusion as a subtheme related to the subject matter. The scarcity of publications on the subject investigated revealed the need for dissemination of studies that amplify the reflections and propositions about the same. Keywords: Generalist teacher; Specialist teacher; Special education.

\section{RESUMEN}

El presente trabajo objetivó identificar y analizar la producción científica nacional divulgada en periódicos del área de Educación Especial sobre las representaciones del profesor generalista acerca del papel del profesor especialista en el proceso de escolarización de los alumnos público-objetivo de la Educación Especial. La investigación bibliográfica consideró los periódicos clasificados en los extractos de B2 a A1: la Revista de Educación Especial de Santa María (REESM); y la Revista Brasileña de Educación Especial (RBEE), respectivamente, así como los artículos publicados en esas revistas, en el período de 2008 a 2015, relacionados con la temática en cuestión. Para la recolección de datos fueron considerados, inicialmente, los sumarios, seguidos de los resúmenes y artículos en su totalidad que atendieron al objetivo propuesto. Se efectuó un análisis cualitativo, subsidiado por los indicadores: año y cantidad de publicación; tipo de autoría; área de formación de los autores y coautores; y temas relacionados a las representaciones del profesor generalista sobre el papel del especialista. Se constató una mayor concentración de artículos publicados en 2015 en el periódico B2, así como predominio: de autoría doble en los dos periódicos; de la Educación como principal área de formación de los autores y coautores; y 
DOI: $10.5902 / 1984644424254$

de la reflexión sobre concepciones de profesores acerca de la inclusión escolar como subtema relacionado a la temática en cuestión. La escasez de publicaciones sobre la temática investigada reveló la necesidad de divulgación de estudios que amplíen las reflexiones y proposiciones sobre la misma.

Palabras clave: Profesor generalista; Profesor especialista; Educación especial.

\section{Introdução}

A Educação Especial, no Brasil, é uma área de conhecimento e pesquisa consolidada, mas o processo de inclusão escolar dos alunos público-alvo dessa área, apesar de ser orientado por leis específicas, ainda encontra-se longe de se concretizar, pois requer mudanças de paradigmas. Está vinculado não apenas a mudanças de infraestrutura, mas também atitudinais e metodológicas (GLAT; PLETSCH, 2010; GIROTO, 2012; GIROTO; MILANEZ, 2013).

Considerando o professor como fundamental para esse processo de mudança de paradigma, percebe-se que, apesar do avanço significativo nas proposições para a formação de professores na perspectiva da educação inclusiva, assentado nas principais normativas educacionais vigentes, a exemplo da Política Nacional de Educação Especial na Perspectiva da Educação Inclusiva (BRASIL, 2008), da Resolução n4/2009 (BRASIL, 2009) e do Decreto no 7.611/2011 (BRASIL, 2011), tal formação ainda pode ser considerada, no âmbito geral, precarizada.

Essa precarização encontra-se, entre outros fatores, intrinsecamente atrelada à maneira como as instituições de ensino superior (IES) têm conduzido as propostas de formação inicial de professores, com grande frequência, distantes da realidade educacional e, em muitas situações, até mesmo distantes do paradigma de inclusão (GLAT; PLETSCH, 2010; GIROTO; BERBERIAN; SANTANA, 2014; SILVA, 2015; POKER; MILANEZ, 2015).

Atrelado a esse fator, as expectativas equivocadamente depositadas apenas no professor como o grande responsável para o sucesso da escola inclusiva corroboram com essa situação e, em decorrência desse equívoco, "[...] o professor, tido como agente de mudança, emerge, pois, cada vez mais, como o responsável pela realização do ideário do século XXI" (SCHEIBE, 2010, p.7).

Ainda que muitas proposições, no âmbito do governo federal, garantidas pelas normativas legais anteriormente citadas, promovam possibilidades de formação do professor na perspectiva da educação inclusiva, os professores, de modo geral e conforme 
DOI: $10.5902 / 1984644424254$

dados da literatura, sentem o despreparo e a formação precarizada para lidar com os alunos público-alvo da Educação Especial: alunos com deficiências, com transtornos globais do desenvolvimento (TGDs) e com altas habilidades/superdotação (GLAT; PLETSCH, 2010; MENDES, ALMEIDA; TOYODA, 2011), pois são muitos os desafios existentes na escolarização desses alunos.

A atual reorganização do sistema educacional na perspectiva da educação inclusiva (BRASIL, 2008; 2009; 2011) assegurou à Educação Especial um caráter transversal e de suporte ao ensino regular, ou seja, esta modalidade educacional passou a ser considerada complementar e não mais substitutiva ao ensino regular, devendo ser oferecida desde a educação infantil até o ensino superior, principalmente por meio da oferta de atendimento educacional especializado (AEE), nas salas de recursos multifuncionais, sob a responsabilidade do professor especialista, cuja formação requer a graduação em Pedagogia ou Normal Superior e pós-graduação lato sensu na área de Educação Especial (BRASIL, 2009).

Sob tal reorganização, entende-se que, ao professor generalista, que atua na classe comum, coube a responsabilização pela alfabetização do público-alvo da Educação Especial, sob o suporte do professor especialista (BRASIL, 2008; 2011). Tal reorganização tem sido alvo de intensos debates, uma vez que, no modelo anterior, esse alunado era alfabetizado nas classes especiais, sob responsabilidade do especialista.

A confusão sobre os papeis desses professores, que parece ter se instalado nos diferentes contextos educacionais, tanto por parte de generalistas, quanto de especialistas tem sido frequente. Soma-se a isso, conforme mencionado, o distanciamento entre as propostas de formação inicial e a realidade educacional, no que se refere à presença maciça do público-alvo da Educação Especial nas escolas, em geral. Situação agravada pelas próprias normativas legais que, em muitos aspectos, são contraditórias, a exemplo da distância entre o que colocam como requisitos, critérios e condições necessárias para a atuação com esse público e o que as propostas de formação inicial de professores contemplam sobre os conteúdos acerca de temas como inclusão, educação inclusiva e Educação Especial (BRASIL, 1996; 2008).

Há que ser destacada também a relação histórica entre a educação geral e a Educação Especial, que muito corroborou para o distanciamento entre o professor generalista e o especialista, no que diz respeito às práticas pedagógicas e atuação 
DOI: $10.5902 / 1984644424254$

colaborativa no processo de escolarização desse alunado (MENDES; ALMEIDA; TOYODA, 2011; GIROTO, 2012).

Ainda tem sido frequente o confronto entre ambos: o professor generalista, muitas vezes acredita que seu papel é o de identificar o alunado e o encaminhar para o AEE, isentando-se assim da função de alfabetização e deixando-a sob a responsabilidade do professor especialista, que não corresponderá a essa expectativa. O professor especialista, por sua vez, dentre suas inúmeras atribuições, tem a responsabilidade pelo suporte ao processo de escolarização desse alunado, por meio do uso de recursos específicos às suas demandas educacionais, a exemplo do ensino de Braille para alunos cegos, não tomando para si a responsabilidade pela alfabetização, que deve ocorrer na sala de aula regular.

Nesse processo, é comum o aluno transitar entre as salas de aula comum e de recursos sem que as práticas pedagógicas utilizadas pelos professores responsáveis por tais salas tenham sido por eles discutidas colaborativamente, pois não se tem a cultura e a infraestrutura, na escola, para o trabalho colaborativo entre esses profissionais. É frequente a falta de conhecimentos, por parte desses profissionais, sobre seus respectivos papeis na escolarização dos alunos público-alvo da Educação Especial (GIROTO; MILANEZ, 2013).

Frente a esse cenário e com vistas ao aprofundamento das discussões acerca dessa temática, o presente trabalho objetivou identificar e analisar a produção científica nacional divulgada em periódicos da área de Educação Especial sobre as representações do professor generalista acerca do papel do professor especialista no processo de escolarização dos alunos público-alvo da Educação Especial.

\section{Metodologia}

Para a consecução dos objetivos propostos, foi realizada uma pesquisa bibliográfica sistematizada, subsidiada por estudos dessa natureza que se referem à análise da produção de conhecimento científico em Educação Especial (MANZINI, 2003; 2011; BUENO, 2008; NUNES; BRAUN; WALTER, 2011; AZEVEDO; GIROTO; SANTANA, 2015). Foram considerados, para tal, os periódicos da área de Educação Especial qualificados nos extratos de B2 a A1, conforme os critérios WebQualis propostos pela Coordenação de Aperfeiçoamento de Pessoal do Ensino Superior (CAPES) e, mais comumente, considerados para fins de classificação em programas de pós-graduação da área de Educação. 
DOI: $10.5902 / 1984644424254$

O período de 2008 a 2015 foi selecionado levando-se em conta o marco político, em 2008, representado pela Política Nacional de Educação Especial na Perspectiva da Educação Inclusiva (BRASIL, 2008), a partir da qual se deu a atual reorganização do sistema educacional inclusivo, até 2015, por representar o ano em que ocorreu a coleta dos dados aqui considerados.

Foram selecionados os dois periódicos classificados nos extratos mencionados: a Revista Brasileira de Educação Especial (RBEE), com Qualis A2, cujos números publicados encontram-se disponíveis, online, na página as Associação Brasileira de Pesquisadores em Educação Especial (ABPEE) e no Scientific Electronic Library Online (Scielo); e a revista de Educação Especial de Santa Maria (REESM), QualisB2, disponibilizada no Scielo, bem como os artigos publicados nesses dois periódicos no período indicado.

A coleta de dados compreendeu, inicialmente, a leitura dos sumários de todos os números produzidos nesses dois periódicos no período considerado. A partir da relação explicita ou implícita do título do artigo com a temática em questão, foi realizada a leitura dos resumos selecionados, para fins de confirmação de tal relação e, posteriormente, foi efetuada a leitura, na íntegra, de todos os artigos que atenderam ao objetivo proposto.

Para a análise qualiquantitativa efetuada foram considerados os seguintes indicadores: a quantidade de artigos por ano de publicação; o tipo de autoria; a área de formação dos autores e coautores; e os subtemas relacionados ao assunto investigado.

\section{Resultados e Discussão}

Cabe ressaltar que, a relação identificada entre os artigos selecionados e a temática investigada foi considerada de natureza implícita, ou seja, embora a temática em questão não tenha sido tratada como foco principal dos artigos selecionados para análise, foi indiretamente mencionada. De forma que todos os artigos que se relacionaram ao trabalho do professor generalista e à atuação do professor especialista no AEE, bem como à articulação entre os serviços educacionais especializados e o ensino regular e ao AEE, propriamente dito, foram aqui considerados, a partir dos indicadores que seguem:

\section{Ano e quantidade de artigos publicados}

Os dados representados no Gráfico1 dizem respeito às publicações dos últimos oito anos localizados na RBEE e na REESM que, implicitamente, foram relacionadas à temática em questão. 
DOI: $10.5902 / 1984644424254$

Gráfico 1 - Distribuição dos artigos publicados de 2008 a 2015 nos dois periódicos

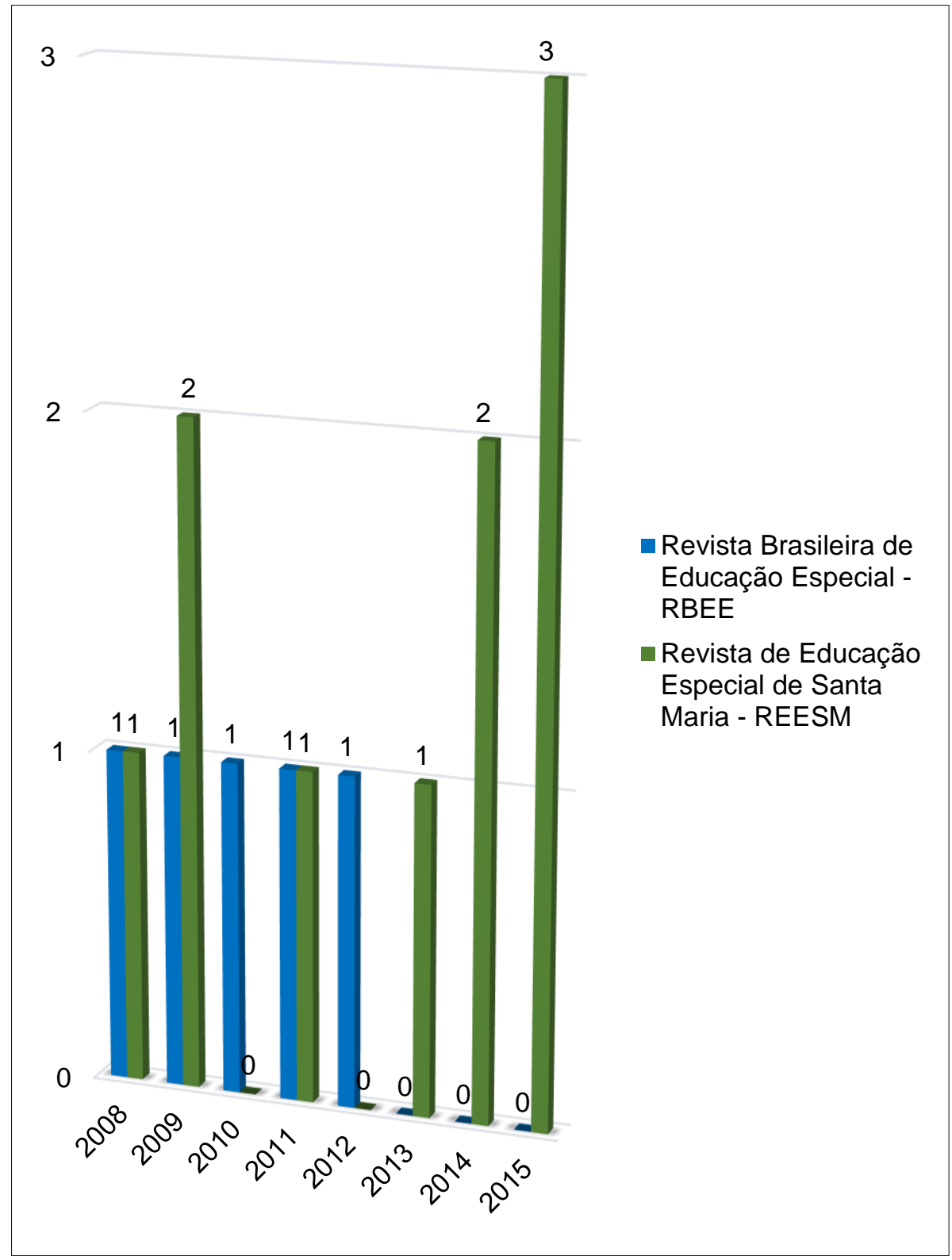

Fonte: Dados da pesquisa

Conforme indicam os dados apresentados no Gráfico 1, em oito anos de publicações da RBEE e da REESM foram localizados 15 artigos implicitamente relacionados ao tema. Nos anos de 2010 e 2012 não foi identificada a ocorrência de publicações na REESM que guardassem relação com a temática em questão, semelhantemente ao que ocorreu nos anos de 2013, 2014 e 2015 na RBEE.

Merece destaque, no caso da REESM, as publicações veiculadas no ano de 2015, visto que esse periódico publicou, nesse ano, um maior número de artigos que, mesmo que 
DOI: $10.5902 / 1984644424254$

indiretamente relacionados à temática proposta, trataram da atuação dos professores generalista e especialista.

Tal fato pode ter sido ocasionado justamente pelo intenso debate que tem ocorrido, mais recentemente, sobre a atual reorganização do sistema educacional na perspectiva da educação inclusiva e os papeis desses professores nesse cenário (GLAT; PLETSCH, 2010; GIROTO, 2012; GIROTO; MILANEZ; 2013; GIROTO; BERBERIAN; SANTANA; 2014).

\section{Tipo de autoria dos artigos publicados}

Conforme o Gráfico 2, é possível observar que, do total de 15 artigos identificados e selecionados para análise, dez $(66,67 \%)$ foram escritos, em sua maioria, em duplas, sendo sete da REESM e três da RBEE. Dois (13,33\%) foram escritos individualmente, sendo um da RBEE e um da REESM. Dois (13,33\%) foram escritos em trios, sendo um em cada revista; e apenas um (6,67\%), da REESM, foi escrito em grupo.

Gráfico 2 - Distribuição do tipo de autoria dos artigos publicados na RBEE e na REESM

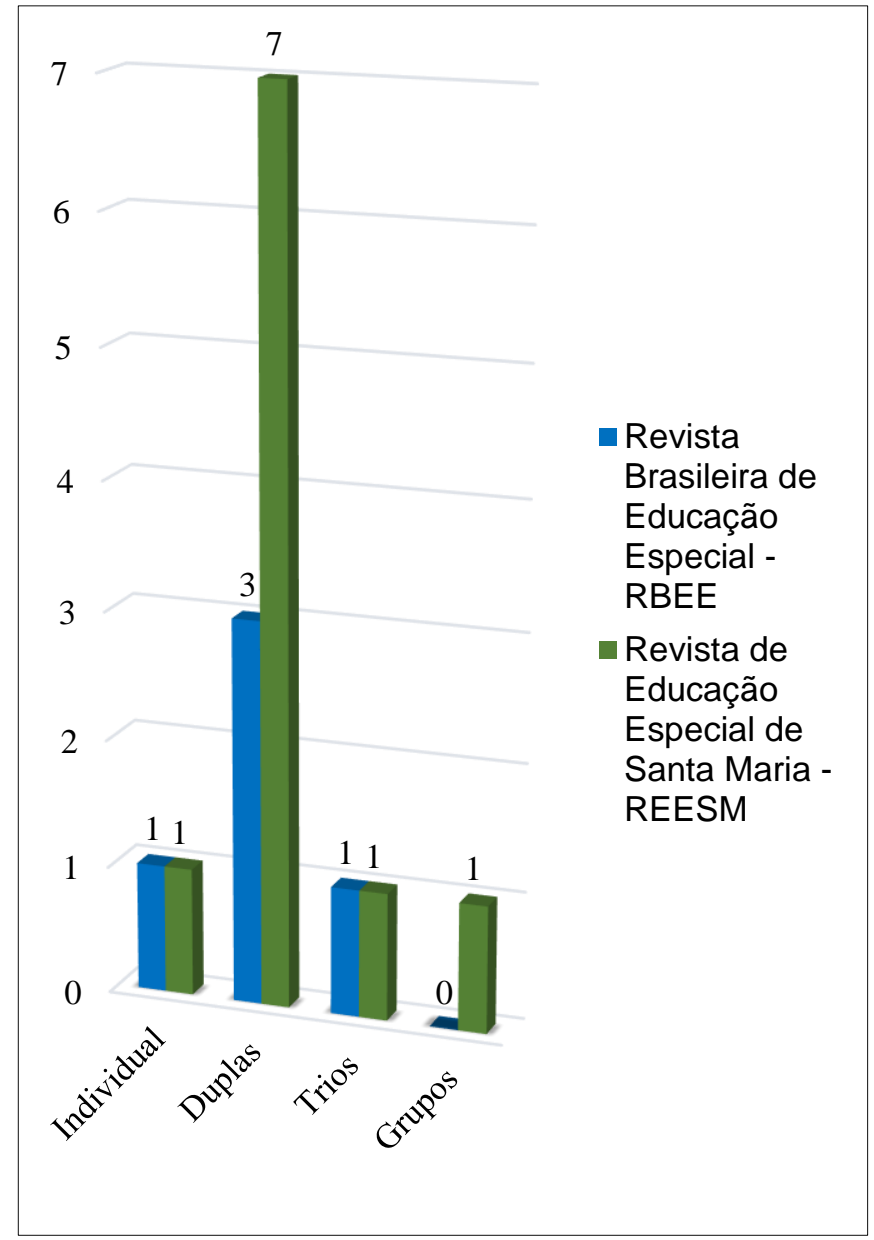

Fonte: Dados da pesquisa 
$\mathrm{Na}$ revista RBEE foram identificados artigos tanto com autoria individual, quanto em duplas ou em trios, do tipo relato de pesquisa, enquanto que na REESM foram localizados artigos publicados individualmente, em duplas, trios e em grupos com mais de três autores, provenientes de pesquisas de trabalhos de conclusão de curso (TCC), de mestrado e de doutorado. O único artigo em grupo identificado, com mais de três autores, foi publicado nesse periódico, proveniente da junção de pesquisadores da saúde e da educação visando à educação inclusiva, com foco na educação especial (ZILLY et al, 2015). Cabe destacar que a prática de publicação em grupo, com mais de três autores, é muito frequente na área da saúde, fato que pode ter corroborado para a ocorrência desse tipo de autoria e parceria.

\section{Áreas de formação dos autores e coautores}

A análise acerca da área de formação dos autores e coautores das publicações pesquisadas revelou o predomínio da formação em educação, representado por 27 $(79,42 \%)$ dos autores somando as duas revistas; seguida da formação em Fisioterapia, com dois $(5,88 \%)$ autores; Terapia Ocupacional, com dois (5,88\%) autores; Psicologia, também com dois $(5,88 \%)$ autores; e apenas um (2,94\%) autor com formação em Enfermagem.

Gráfico 3 - Distribuição das publicações consultadas por área de formação dos autores e coautores

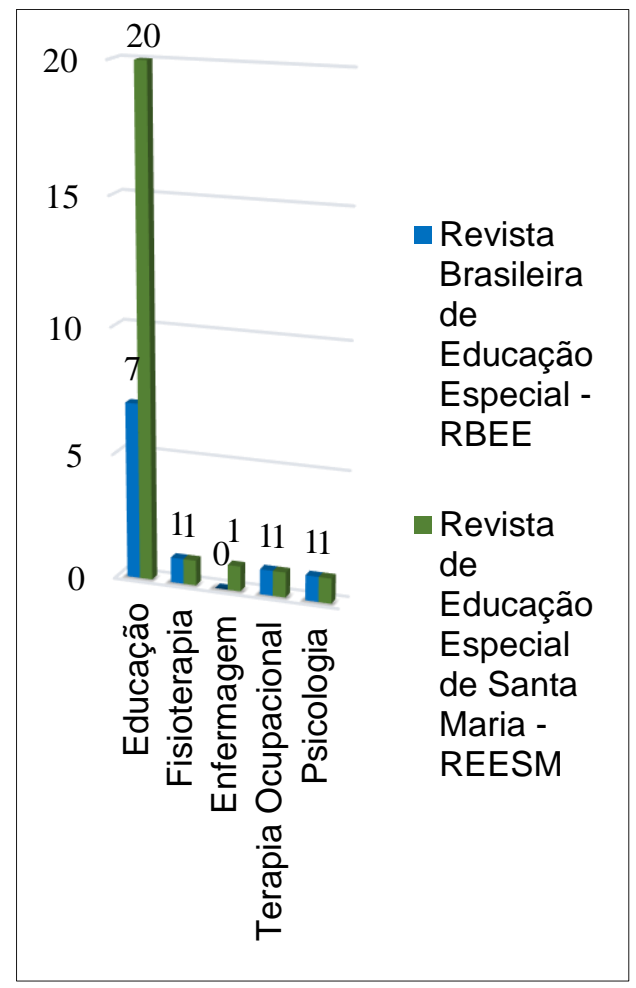

Fonte: Dados da pesquisa 
Tendo em vista que, tanto a RBEE quanto a REESM são periódicos da área de Educação Especial, contemplada na área da Educação, para fins de classificação no WebQualis, o sistema de classificação de periódicos da CAPES, ao qual os programas de pós-graduação comumente recorrem também para fins de classificação e pontuação dos artigos e periódicos considerados para os índices de produtividade desses programas e de seus respectivos docentes credenciados, é de se esperar o predomínio da área da Educação como área de formação dos autores e coautores dos artigos identificados e analisados no presente trabalho. Tal dado corrobora a informação sobre o predomínio de autoria em duplas, mencionada anteriormente, mais frequentemente relacionada à autoria de orientandos e orientadores que publicaram dados de pesquisas científicas desenvolvidas no âmbito da pós-graduação.

\section{Subtemas relacionados às representações do professor generalista sobre o papel do especialista}

A partir da leitura, na íntegra, dos 15 artigos que constituiu a amostra aqui considerada, foi possível identificar os assuntos abordados que se relacionaram, ainda que implicitamente, à temática ora proposta e que, doravante, são aqui considerados como subtemas relacionados às representações do professor generalista sobre o papel do especialista.

No Gráfico 4 encontram-se representados os dados acerca dos subtemas identificados: 
Gráfico 4 - Distribuição dos artigos publicados de acordo com os subtemas relacionados à temática investigada

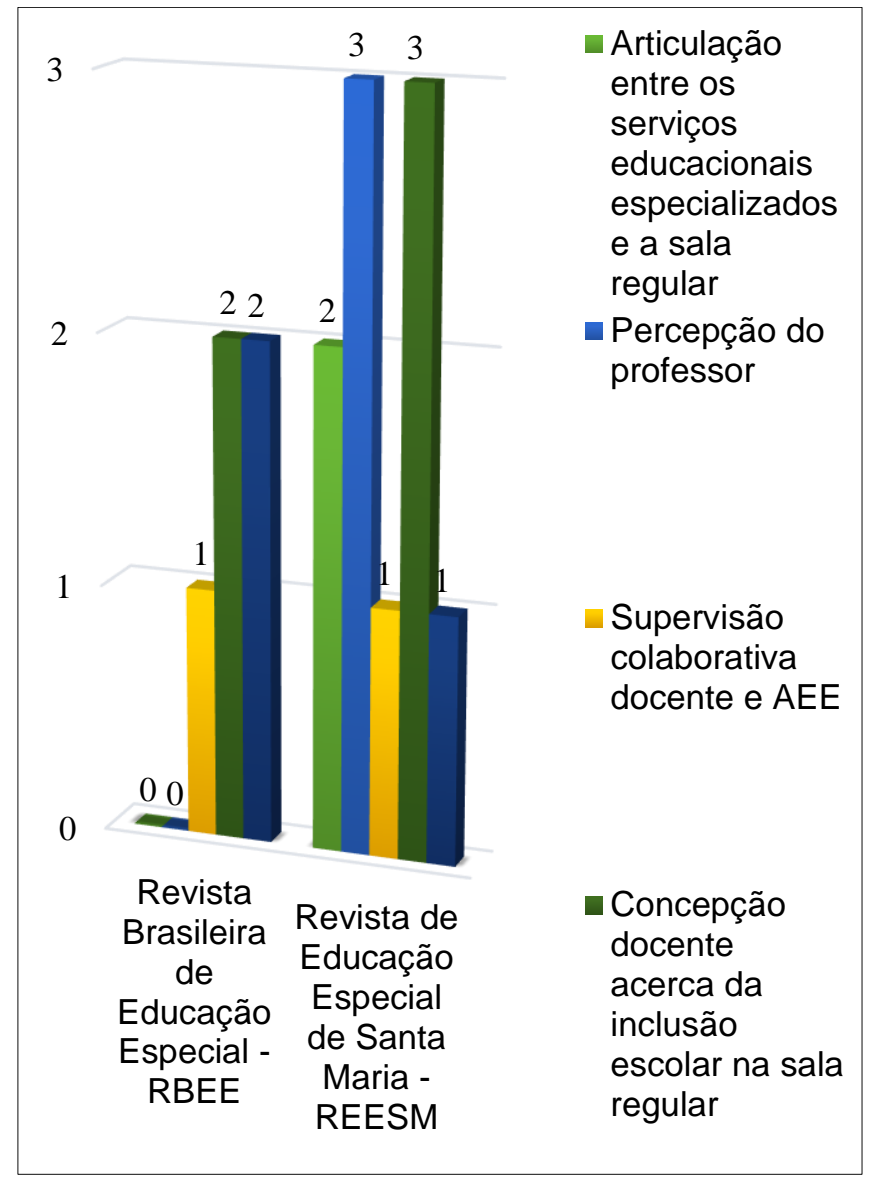

Fonte: Dados da pesquisa

Seguem, abaixo, brevemente descritas, as principais características dos artigos selecionados, de acordo com seus principais objetos de pesquisa, aqui tratados como subtemas relacionadas à temática ora investigada:

\section{Articulação entre os serviços educacionais especializados e a sala regular}

Dois (13,33\%), dos 15 artigos selecionados, foram agrupados nessa temática, por abordarem temas relativos à realidade, dificuldade e despreparo do professor, em sala de aula regular e salas de ensino especial e às práticas político pedagógicas e suas aplicações legais e efetivas, enfocando também algumas deficiências específicas e as suas demandas pedagógicas. Esses dois artigos foram publicados na Revista de Educação Especial de Santa Maria (DELPRETTO; SANTOS, 2013; FUCK; CORDEIRO, 2014). 
DOI: $10.5902 / 1984644424254$

Delpretto e Santos (2013) enfatizaram a discussão sobre a atual reorganização do sistema educacional, na perspectiva da educação inclusiva, com destaque para a discussão acerca da oferta do AEE nesse contexto. Vale ressaltar, ainda, que, segundo esses autores, a articulação da escola regular com os centros de AEE não garante uma efetiva colaboração. Embora haja articulação, ainda há uma grande falta de recursos para que esse trabalho colaborativo ocorra de forma apropriada.

Fuck e Cordeiro (2014) focaram na concepção dos professores da sala regular em relação à atuação do especialista na sala de recursos, além de abordar quais são suas dificuldades e necessidades. Os autores destacaram a inclusão como uma responsabilidade de toda a escola e mencionaram a falta de articulação entre os professores.

Ainda que a articulação entre esses profissionais careça de investimentos, cabe considerar, também, a notável falta de organização da escola e do sistema educacional, em geral, no sentido de comportar situações, atividades e horários que fomentem, incentivem e materializem a atuação colaborativa entre esses profissionais (GIROTO; MILANEZ, 2013).

\section{Percepção do professor da sala de recursos sobre inclusão escolar}

Três artigos (20\%) representaram essa temática. Esses artigos avaliaram a percepção dos professores especialistas que atuam nas salas de recursos de escolas municipais sobre a inclusão escolar, tendo sido publicados, um em dupla, um em trio e um em grupo na REESM (REGANHAN; MANZINI, 2009; SANTOS; CORREIA; CRUZ-SANTOS, 2014; ZILLY et al, 2015).

Reganhan e Manzini (2009) discutiram como os professores do ensino regular usam os recursos pedagógicos para favorecer o aprendizado dos seus alunos com deficiências. Ressaltaram que, a base teórica é de extrema importância para uma prática mais inclusiva. Descreveram a falta de conhecimento sobre recursos para o ensino de alunos com certos tipos de deficiências como uma barreira para o ensino inclusivo. Apontaram que as estratégias de ensino são as menos conhecidas e que há escassez de estudos que ampliem a discussão sobre as mesmas.

Santos, Correia e Cruz-Santos (2014) abordaram o tema da inclusão de alunos com deficiências e NEE na sala de ensino comum, numa determinada região de Portugal. Com este estudo concluíram que alguns dos fatores essenciais para que a inclusão 
DOI: $10.5902 / 1984644424254$

educacional ocorra são as atitudes, os recursos e a colaboração. A primeira medida a ser adotada no país para que a inclusão ocorra é a tomada de consciência de que a inclusão é necessária e, para que isso ocorra, é essencial melhorar os programas de formação de professores, além de possibilitar o acesso a recursos especializados para alunos com NEE.

No artigo de Zilly et al (2015) foi abordada a qualidade do AEE oferecido em salas de recursos de escolas de um município paranaense, no qual há, na opinião desses autores, um serviço educacional especializado de qualidade, mesmo com a necessidade de algumas mudanças a serem realizadas. Nessas salas de recursos que foram consideradas no referido artigo, mencionaram a participação de um profissional da saúde, fato ao qual atribuíram relevância, pois, de acordo com tais autores, este pode contribuir com uma rigorosa avaliação dos alunos, além de prover informações necessárias para melhorar o processo de aprendizagem dos mesmos.

\section{Supervisão colaborativa docente e AEE}

Dois artigos (13,33\%), um artigo publicado na RBEE e outro na REESM, abordaram a colaboração entre os pares dentro da escola e a melhora dos resultados quando esta colaboração é trabalhada a partir da supervisão escolar (LOPES; MARQUEZINE, 2012; GOMES; VIEIRA, 2015).

Lopes e Marquezine (2012) buscaram mostrar o papel de cada profissional envolvido com a inclusão de alunos com deficiências na sala de ensino regular, bem como ocorre a articulação do ensino regular com centros que oferecem o serviço de AEE. Apontaram que um dos obstáculos para o processo de inclusão refere-se a situações em que o aluno encontra-se matriculado concomitantemente em duas instituições, a de ensino regular e obrigatório e outra que ofereça os serviços de AEE. Essas duas instituições, geralmente, não possuem afinidades no que diz respeito a conteúdos trabalhados com os alunos, ou seja, não há comunicação entre os professores da sala de ensino regular e os professores da sala de recursos, muitas vezes devido à insegurança que ambos sentem em relação ao trabalho conjunto, ou por não saberem, ao certo, quais as NEE do alunado da Educação Especial.

Gomes e Vieira (2015) discutiram a importância do AEE, focando nos fatores que facilitam o trabalho colaborativo na sala de recursos multifuncionais. As autoras afirmaram que o trabalho conjunto entre o professor da sala regular e o professor da Educação Especial é essencial para o sucesso de uma educação inclusiva. Entrevistaram professores 
DOI: $10.5902 / 1984644424254$

que alegaram que há uma cultura da falta de comunicação, da qual decorre o atual modelo de supervisão colaborativa, que não visa à melhoria do sistema educacional, mas é um modelo que incita a competição entre os professores, o que pode levar a supervisão colaborativa à ruína.

Em acréscimo a esses aspectos destacados por esses autores, vale ressaltar que, em muitas situações, os professores não têm conhecimento sobre os papeis que necessitam assumir no processo de escolarização dos alunos público-alvo da Educação Especial (GLAT; PLETSCH, 2010; GIROTO; MILANEZ, 2013).

\section{Concepção docente acerca da inclusão escolar na sala regular}

Cinco artigos (33,34\%), sendo três da REESM e dois da RBEE, abordaram a concepção do professor da sala regular em relação à inclusão escolar (QUATRIN; PIVETTA, 2008; MANZINI; MONTEIRO, 2008; ALBUQUERQUE; MACHADO, 2009; VITTA; VITTA; MONTEIRO, 2010; COSTA, 2015).

Quatrin e Pivetta (2008) destacaram que a inclusão é vista, principalmente, como uma medida social muito positiva, embora ainda haja muito despreparo por parte dos professores. Ressaltaram que há poucos relatos de como ocorre, de fato, a inclusão escolar e justificaram tal fato, principalmente, por falta de despreparo e de uma formação precária dos professores. Mencionaram a participação da família como essencial para que o processo de inclusão ocorra de forma correta.

De acordo com o estudo de Monteiro e Manzini (2008), a presença do aluno deficiente no ensino comum ainda traz à tona o paradigma da normalização. O referido estudo indicou que a mudança de concepção encontra-se, fortemente, ligada às intervenções feitas pelo professor.

Albuquerque e Machado (2009) enfatizaram a mudança atitudinal em relação à educação inclusiva, apontando que muitas vezes alguns profissionais envolvidos com a Educação Especial ocupam um papel mais maternal em relação ao aluno, negligenciando assim, o ensino do conteúdo que é garantido por lei para esse aluno. Essas autoras afirmaram, ainda, que, nessa perspectiva, na qual a inclusão é um processo que engloba todas as pessoas da escola, muitas vezes o trabalho docente encontra-se prejudicado, pois pode ficar dependente de uma mudança apenas atitudinal. 
DOI: $10.5902 / 1984644424254$

Vitta, Vitta e Monteiro (2010) focaram a perspectiva dos professores em relação aos alunos deficientes. O principal objetivo em relação aos alunos deficientes, de acordo com esses autores, é a melhoraria de suas habilidades sociais.

Costa (2015) buscou problematizar a formação dos professores e a prática inclusiva. A grande crítica do texto refere-se à falta de formação teórica da qual a maioria dos cursos de formação de professores padece, pois seria justamente o domínio teórico que faria com que muitas práticas fossem melhoradas ou melhor aplicadas. Ressaltou, ainda, que, o domínio teórico, que provem de uma boa formação, é a chave para que a inclusão ocorra da forma ideal.

\section{Uso de tecnologias assistivas}

Três artigos abordaram esse tema, (20\%), dois na RBEE e outro publicado na REESM. Esses artigos discorreram sobre as possibilidades do uso, na sala de recursos, das diversas tecnologias assistivas disponíveis direcionadas às deficiências, provocando reflexões sobre a realidade tanto do uso, quanto do conhecimento, por parte dos profissionais, acerca de tais tecnologias (PELOSI; NUNES, 2009; ASSIS; MARTINEZ, 2011; BAPSTISTA, 2011).

O estudo de Pelosi e Nunes (2009) mostrou que o papel do professor pouco mudou, embora haja muitas mudanças que precisam ser feitas em relação à sua formação, além da necessidade de ampliação dos conhecimentos dos professores sobre as tecnologias assistivas.

Assis e Martinez (2011) debateram a questão da inclusão escolar ressaltando a necessidade de proporcionar igualdade de oportunidades. Tais autores mencionaram que o processo de inclusão continua lento e gradual por falta de conhecimentos práticos sobre recursos que podem ser usados nas salas de AEE. Esses autores acrescentaram ser necessária a melhoria na formação dos professores, além da implementação de mais materiais nas salas de AEE. Consideraram que o grande desafio se dá pela contradição entre os discursos que são pregados a respeito da inclusão escolar e as práticas que, de fato, ocorrem.

Baptista (2011) empreendeu uma discussão acerca da implantação lenta e gradual de tecnologias assistivas, nas salas de recursos multifuncionais, e a falta de espaços físicos apropriados para acomodar tal uso. A sala de recursos é vista, segundo esse autor, como uma sala apenas para alunos com necessidades educacionais especiais (NEE) e para o 
DOI: $10.5902 / 1984644424254$

professor especialista. Para que o uso correto dessa sala e de seus materiais ocorra, é necessária uma mudança de perspectiva e também uma melhora na formação pedagógica do professor.

\section{Conclusões}

A leitura e análise dos artigos sobre o tema proposto conduziu a reflexões acerca do trabalho dos professores na sala de aula regular e nas salas de recursos. Entretanto, foi possível constatar a escassez de estudos, na área de Educação Especial, nos periódicos qualificados nos extratos Web Qualis B2 a A2, que ampliem a discussão acerca das expectativas de professores do ensino regular sobre o papel do professor especialista, uma vez que o trabalho colaborativo tem sido apregoado, nas políticas educacionais vigentes como necessário e fundamental para a escolarização dos alunos público-alvo da Educação Especial. Dessa forma, discutir sobre seu próprio papel e o do especialista, em tal processo, faz-se necessário para que essa colaboração seja concretizada nos diferentes contextos educacionais nos quais esse público encontra-se presente.

Ainda que os artigos identificados abordassem a atuação desses profissionais em seus respectivos ambientes de trabalho (sala regular, no caso do generalista, e sala de recursos multifuncionais, no que diz respeito ao especialista), não trataram, diretamente, da atuação colaborativa entre os mesmos, tampouco explicitaram a compreensão desses profissionais sobre seus próprios papeis e acerca da compreensão que cada um tem sobre as atribuições do outro.

Cabe considerar que, a falta de comunicação entre esses profissionais parece constituir-se numa das grandes barreiras, não apenas ao processo de inclusão dos alunos público-alvo da Educação Especial, como também à atuação pedagógica colaborativa entre tais professores.

Dessa forma, o cenário revelado pelos dados apresentados permite considerar a necessidade de investimentos em pesquisas que abordem: a compreensão desses professores acerca de seus papeis no processo de escolarização do alunado da Educação Especial; e a atuação pedagógica colaborativa na educação inclusiva, perpassada, dentre outros aspectos, pela discussão acerca das práticas pedagógicas utilizadas e das possibilidades de organização escolar para acomodar essa atuação colaborativa. 


\section{Referências}

ALBUQUERQUE, E. R.; MACHADO, L. B. "Sem amor não se consegue desenvolver um bom trabalho": análise das representações sociais de professoras sobre a inclusão escolar. In: Rev. Educ. Espec., Santa Maria, v. 22, n. 33, p. 73-84, 2009. Disponível em: $<$ http://cascavel.ufsm.br/revistas/ojs2.2.2/index.php/educacaoespecial/article/view/170>. Acesso em: 20 abr. 2016.

ASSIS, C. P. C.; MARTINEZ, M. S. A inclusão escolar e utilização de tecnologia assistiva para alunos com sequelas de mielomeningocele: a opinião dos professores. In: Rev. Educ. Espec., Santa Maria, v. 24, n. 39, p. 93-112, 2011. Disponível em: <http://www.ufsm.br/revistaeducacaoespecial>. Acesso em: 02 jan. 2016.

AZEVEDO, C. B.; GIROTO, C. R. M.; SANTANA, A. P. Produção Científica na Área da Surdez: Análise dos Artigos Publicados na Revista Brasileira de Educação Especial no Período de 1992 a 2013. In: Rev. Bras. Ed. Esp., Marília, v. 21, n. 4, p. 459-476, 2015.

BAPTISTA, C. R. Ação pedagógica e educação especial: a sala de recursos como prioridade na oferta de serviços especializados. In: Rev. Bras. Ed.Esp., Marília, v.17, p. 59-76, 2011. Ed. Esp. Disponível em: <http://www.scielo.br/pdf/rbee/v17nspe1/06.pdf>. Acesso em: 06 fev. 2016.

BUENO, J. G. S. A produção acadêmica sobre inclusão escolar e educação inclusiva. In: MENDES, E. G.; ALMEIDA, M. A.; HAYASHI, M. C. P. I. (Org.). Temas em Educação Especial: conhecimentos para fundamentar a prática. Araraquara: Junqueira \& Marin; Brasília, DF: CAPES-PROESP, 2008, p.31-47.

BRASIL. Lei no 9.394/1996. Estabelece as diretrizes e bases da educação nacional. Disponível em: $<$ http://portal.mec.gov.br/seed/arquivos/pdf/tvescola/leis/lein9394.pdf>. Acesso em: 20 abr. 2016.

Política Nacional de Educação Especial na Perspectiva da Educação Inclusiva. Dispõe sobre a educação especial, o atendimento educacional especializado e dá outras providências. Disponível em: $<$ http://peei.mec.gov.br/arquivos/politica_nacional_educacao_especial.pdf>. Acesso em: 11 abr. 2016.

Resolução N. 4/2009. Institui Diretrizes Operacionais para o Atendimento Educacional Especializado na Educação Básica, modalidade Educação Especial. Disponível em: <http://peei.mec.gov.br/arquivos/Resol_4_2009_CNB.pdf>. Acesso em: 11 abr. 2016.

Decreto 7.611/2011. Dispõe sobre a educação especial, o atendimento educacional especializado e dá outras providências. Disponível em: <http://www.planalto.gov.br/ccivil_03/_Ato2011-2014/2011/Decreto/D7611.htm>. Acesso em: 11 abr. 2016. 


\section{DOI: $10.5902 / 1984644424254$}

COSTA, V. A. Formação de professores e sua relação com a educação inclusiva: desafios à experiência teórica na práxis pedagógica. In: Rev. Educ. Espec., Santa Maria, v. 28, n. 52, p. 405-416, 2015. Disponível em: $<$ http://cascavel.ufsm.br/revistas/ojs-

2.2.2/index.php/educacaoespecial/article/view/16093>. Acesso em: 20 abr. 2016.

DELPRETTO, B. M. L.; SANTOS, B. C. C. Um contexto em transformação político pedagógico: A articulação entre uma escola regular e um centro de atendimento educacional especializado. In: Rev. Educ. Espec., Santa Maria, v. 26, n.4, p. 727742, 2013. Disponível em: <http://www.ufsm.br/revistaeducacaoespecial>. Acesso em: 03 fev. 2016.

FUCK, A. H.; CORDEIRO, A. F. M. As professoras da sala comum e seus dizeres: Atendimento Educacional Especializado nas salas de recursos multifuncionais. In: Rev. Educ. Espec., Santa Maria, v.28, n. 52, 2015. Disponível em: $<$ http://cascavel.ufsm.br/revistas/ojs-

2.2.2/index.php/educacaoespecial/article/view/16093>. Acesso em: abr. 2016.

GIROTO, C. R. M. Reflexões sobre a formação do professor para o Atendimento Educacional Especializado no contexto das atuais políticas educacionais. In: SOUZA, C. B. G.; RIBEIRO, P. R. M. (Org.). Políticas públicas em educação no contexto ibero-americano, São Paulo: Cultura Acadêmica, 2012, p. 27-39.

GIROTO, C. R. M.; MILANEZ, S. G. C. La formación del profesorado de apoyos educativos especializados: ¿qué ha cambiado en la practica docente especializada en el escenario educativo de Brasil. In: HEREDERO, E. S.; GIROTO, C. R. M.; MARTINS, S. E. S. O. (Org.). La formación del profesorado para la atención a la diversidad en Brasil y España. Alcalá de Henares/Espanha: Servicio de Publicaciones de la Universidad de Alcalá de Henares, 2013, p. 05-218.

GIROTO, C. R. M.; BeRBERIAN, A. P.; SANTANA, A. P. O. Salud, Educación y Educación Especial: principios y paradigmas guías de las prácticas en salud en el contexto educativo inclusivo. In: GIROTO, C. R. M. et al. (Org.). Servicios de apoyo en Educación Especial: una mirada desde diferentes realidades. Alcalá de Henares/Espanha: Servicio de Publicaciones de la Universidad de Alcalá de Henares, 2014, p. 115-138.

GLAT, R.; PLETSCH, M. D. O papel da Universidade no contexto da política de Educação Inclusiva: reflexões sobre a formação de recursos humanos e a produção de conhecimento. Rev. Bras. Ed. Esp., v. 23, n. 38, p. 345-356, 2010.

GOMES, A. M. P. M.; VIEIRA, M. C. M. A importância da supervisão colaborativa no desenvolvimento profissional do docente de educação especial. In: Rev. Educ. Espec., Santa Maria, v. 28, n. 53. p. 751-764, 2015. Disponível em: <http://www.ufsm.br/revistaeducacaoespecial>. Acesso em: 04 fev. 2016.

LOPES, E; MARQUEZINE, M. C. Sala de recursos no processo de inclusão do aluno com deficiência intelectual na percepção dos professores. In: Rev. Bras. Ed. Esp., 
DOI: $10.5902 / 1984644424254$

Marília, v. 18, n. 3, p. 487-506, 2012. Disponível em: <http://www.scielo.br/pdf/rbee/v18n3/a09.pdf>. Acesso em: 05 fev. 2016.

MANZINI, E. J. Análise de artigos da Revista Brasileira de Educação Especial (1992 - 2002). In: Rev. Bras. Ed. Esp., Marília, v.9, n.1, p.13-23, 2003.

Tipo de conhecimento sobre a inclusão produzido pelas pesquisas. Rev. Bras. Ed. Esp., Marília, v.17, n.1, p.53-70, 2011.

MANZINI, E. J.; MONTEIRO, A. P. H. Mudanças nas concepções do professor do ensino fundamental em relação à inclusão após a entrada de alunos com deficiência em sua classe. In: Rev. Bras. Ed. Esp., Marília, v. 14, n.1, p. 35-52, 2008. Disponível em: $\quad<h t t p: / / w w w . s c i e l o . b r / s c i e l o . p h p ? s c r i p t=s c i \_a r t t e x t \& p i d=S 1413-$ 65382008000100004>. Acesso em: 20 abr. 2016.

MENDES, E. G.; ALMEIDA, M. A.; TOYODA, C. Y. Inclusão escolar pela via da colaboração entre educação especial e educação regular. Educar em Revista, n. 41, p. 80-93, 2011. Disponível em: <http://hdl.handle.net/11449/29852>. Acesso em: 15 mai. 2016.

NUNES, L. R. O. P.; BRAUN, P.; WALTER, C. C. F. Procedimentos e recursos de ensino para o aluno com deficiência: o que tem sido disseminado nos trabalhos do GT 15 da ANPED sobre estes temas? Ver. Bras. Ed. Esp., Marília, v.17, ed. esp, p.2340, 2011.

PELOSI, M. B.; NUNES, L. R. O. P. Caracterização dos professores itinerantes, suas ações na área de tecnologia assistiva e seu papel como agente de inclusão escolar. In: Rev. Bras. Ed. Esp., v. 15, n.1, Marília, p. 141-154, 2009. Disponível em: $<$ http://www.scielo.br/scielo.php?pid=S1413-

5382009000100010\&script=sci_abstract\&tlng=pt>. Acesso em: 20 abr. 2016.

POKER, R. B.; MILANEZ, S. G. C. Formação do professor e educação inclusiva: análise dos conteúdos dos cursos de pedagogia da UNESP e da USP. In: Revista Ibero-americana de Estudos em Educação, v. 10, n. esp., p. 703-718, 2015. Disponível em: http://seer.fclar.unesp.br/iberoamericana/article/view/7921/5428>. Acesso em: 20 abr. 2016.

QUATRIN, L. B.; PIVETTA, H. M. F. Inclusão escolar e concepções docentes: do desejo idealizado à realidade prática. In: Rev. Educ. Espec., Santa Maria, n. 31, p. 49-62, 2008. Disponível em: <http://www.ufsm.br/ce/revista>. Acesso em: 02 jan. 2016.

REGANHAN, W. G.; MANZINI, E. J. Percepção de professores do ensino regular sobre recursos e estratégias para o ensino de alunos com deficiência. In: Rev. Educ. Espec., Santa Maria, v. 22, n. 34, p. 127-138, 2009. Disponível em: $<$ http://cascavel.ufsm.br/revistas/ojs-2.2.2/index.php/educacaoespecial>. Acesso em: 20 abr. 2016. 


\section{DOI: $10.5902 / 1984644424254$}

SANTOS, A. F.; CORREIA, L. M.; CRUZ-SANTOS, A. Percepção de professores face à educação de alunos com necessidades educativas especiais: um estudo no norte de Portugal. In: Rev. Educ. Espec., Santa Maria, v. 27, n. 48, p. 11-25, 2014. Disponível em: <http://cascavel.ufsm.br/revistas/ojs2.2/index.php/educacaoespecial/article/view/9013 >. Acesso em: 20 abr. 2016.

SCHEIBE, L. Valorização e formação dos professores para a educação básica: questões desafiadoras para um novo Plano Nacional de Educação. In: Rev. Educ. Soc., Campinas, v. 31, n. 112, 2010.

SILVA, L. C. Formação de professores: desafios à educação inclusiva. In: Revista Ibero-americana de Estudos em Educação, v. 10, n. esp., p. 691-701, 2015. Disponível em: <http://seer.fclar.unesp.br/iberoamericana/article/view/7920/5427>. Acesso em: 20 abr. 2016.

VITTA, F. C. F.; VITTA, A.; MONTEIRO, A. S. R. Percepção de professores de educação infantil sobre a inclusão da criança com deficiência. In: Rev. Bras. Ed. Esp., Marília, v.16, n.3, p. 415-428, 2010. Disponível em: <http://www.scielo.br/scielo.php?script=sci_arttext\&pid=S141365382010000300007>. Acesso em: 20 abr. 2016.

ZILLY, A. et al. Percepção de professores das salas de recursos em uma rede de ensino municipal do Paraná. In: Rev. Educ. Espec., Santa Maria, v. 28, n. 51, p. 131 148, 2015. Disponível em: <http://www.ufsm.br/revistaeducacaoespecial>. Acesso em: 05 fev. 2016.

\section{Correspondência}

Claudia Regina Mosca Giroto - Universidade Estadual Paulista Júlio de Mesquita Filho. Av. Higino Muzzi Filho, 737,Vila Universitária Mirante, CEP: 17525-900, Marília, São Paulo, Brasil.

This work is licensed under a Creative Commons Attribution-NonCommercial 4.0 International (CC BY-NC 4.0) 